\title{
Ship Collision Risk Assessment at Water Area of Container Terminal due to Marine Traffic in the Surabaya West Access Channel
}

\author{
A.A.B. Dinariyana*, K.B. Artana and Pandhu H. Amarta \\ Department of Marine Engineering, Institut Teknologi Sepuluh Nopember, Surabaya, Indonesia \\ kojex@its.ac.id \\ *corresponding author
}

Keywords: Ship Collision, Risk Assessment, Structural Damage

\begin{abstract}
This paper addresses a study on risk assessment of ship collision in water area of Container Terminal in the Surabaya West Access Channel (SWAC). The SWAC is the one of the busiest access channels in Indonesia which located between eastern part of Java and Madura Islands. Hence, to provide the safe operation of ships, it is important to assess the risk due to existence of marine traffic in this water area. In this study, the risk assessment also considered future traffic due to future development in this area. It is expected that Java Integrated Industrial and Port Estate (JIIPE) with several new development of industrial ports will contribute to the increase of shipping traffic in SWAC. The risk assessment is conducted for both analyzing annual frequency of collision and consequence of collision by analyzing the damage of ship structures. The annual frequency of collision is done using numerical calculation based on IWRAP theory developed by Peter Friis-Hansen. The ship structural damage analysis to determine the impact of ship collision is done using 3D model. The risk due to collision of ships in this area is considered as acceptable risk if the frequency of ship collision is less than unity (one collision per year). The structural damage analysis gives the result of external dynamics when two ships are collided.
\end{abstract}

\section{Introduction}

Sea transportation is one method for transporting goods that delivers high rate of tonnage in affordable price. In Indonesia, the demand of sea transportation has been increasing in line with the development growth and economic activities in the regions. Surabaya West Access Channel (SWAC) is considered as the one of the busiest shipping access channels in Indonesia where several industrial ports are being operated and new ports are also expected to be developed in this area. SWAC is located between eastern part of Java Island and Madura Island with the water depth approximately is $14 \mathrm{~m}$ [1]. There are various types of ship that pass through the channel and the number of ships is expected to increase in the future due to massive development in this area. Risk Assessment is a method to ensure that the risk of ship collision is still acceptable.

Port of Tanjung Perak is one of ports that located in the SWAC. Port of Tanjung Perak serves several types of ships including passenger ships, general cargo ships, and container ships. This study aims to determine the level of risk in one container terminal belongs to the Port of Tanjung Perak due to marine traffic in the vicinity of the terminal. To determine the level of risk due to the existence of 
marine traffic in this water area, risk assessment due to collision is proposed in this study. The risk assessment is done by analyzing annual frequency of collision and analyzing the structural damage due to collision between two ships. The frequency analysis is done using IWRAP theory that firstly proposed by Friis-Hansen [2]. Three scenarios of collision are analyzed namely, crossing collision, head-on collision, and overtaking collision. The level of risk in term of annual frequency is considered as acceptable risk when the annual frequency of collision is less than unity (one collision per year).

The analysis of ship collision consequence is done using damage structural analysis by modeling the ships using 3D software to determine the external dynamics as the impact of ship collision. For consequence analysis, to simplify the scenario of crossing collision, the impact of two ships is modeled using two sections of ships, a bulbous bow of ship colliding to midship section of other ship. The impact between two sections is used to determine the deformation and stress which is produced as the effect of collision. The external dynamics analysis illustrates the result of collision energy which is dissipated by the ship structure [3]. The result will show the deformation as the effect of crossing collision. This method is used to produce accurate result according to the explicit dynamics model application.

This paper is organized as follows. Section II explains the frequency of ship collision by giving three scenarios of collision; crossing collision, head-on collision, and overtaking collision. IWRAP theory that is use as the mathematical method to conduct the analysis of ship collision will be validated using IWRAP Mk2, a modeling tool useful for maritime risk assessment. Section III, describe the procedure of consequence analysis in term of structural damage analysis due to the impact of ship collision. Impact analysis is conducted by determining external dynamic using 3D modelling. Section IV shows the result of frequency analysis of ship collision analysis and the result consequence analysis follows with conclusion in Section V.

\section{Ship Collision Frequency Analysis}

\subsection{Area of Study}

The location of study where the risk assessment of ship collision can be seen in Fig. 1 as the model of ship route and defined as normal distibution in each leg. This segment was chosen and considered since this water area has a considerably high traffic volume. The density of ship that operated in this area has been obtained using automatic identification system (AIS) data. This water area is affected by ships heading to Madura Strait, ships entering container terminal and Port of Tanjung Perak, and ships heading to SWAC. Based on the data obtained from port authority, there are 8.275 ships operated in this area in 2016. The ships consist containerships, general cargo ships, passenger ships, and others.

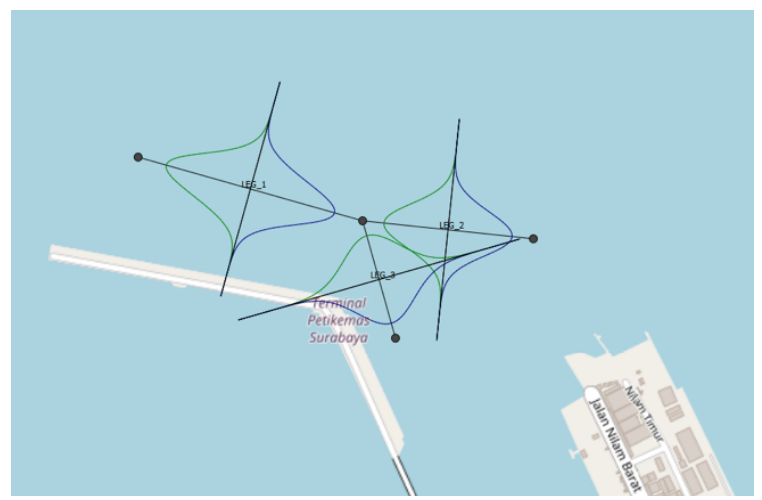

Fig. 1. The studied area is close to Terminal Peti Kemas Surabaya Port marked with leg illustration on the map. 


\subsection{Data for Ship Collision Frequency Analysis}

In this paper, the data used for frequency analysis was obtained from two sources such as:

- Data reported from AIS as the dynamic data which to be used for analyzing the shipping pattern in the water area. The AIS data is also utilized as an input to IWRAP software to obtain the density plot along the segment and several data related to conduct risk assessment.

- Traffic data obtained from Port Authority of Tanjung Perak as the static data since not all of ships that passing through the SWAC operate the AIS device properly and to support several ship data that may not be reported completely by the AIS device.

The data is then processed for clustering the ship according to ship length and ship type. The clustering is an important step in order to conduct further analysis in IWRAP. Moreover, the ship clustering is also used for determining collision frequency for each ship type and length. Table 1 shows the result of ship clustering according to its length and type. The average of ship length and breadth for each group will be used in the analysis.

Table 1: Ship's Clustering

\begin{tabular}{ccccccc}
\hline \multirow{2}{*}{$\begin{array}{c}\text { Length } \\
\text { (meter) }\end{array}$} & Tanker & CNTR & Ro-Ro & Support & Cargo & PAX \\
\cline { 2 - 7 } & 3 & 0 & 0 & 10 & 3 & 0 \\
\hline $0-25$ & 178 & 27 & 26 & 231 & 375 & 65 \\
$25-50$ & 319 & 278 & 182 & 231 & 776 & 36 \\
$50-75$ & 242 & 1267 & 189 & 14 & 267 & 206 \\
$75-100$ & 84 & 1157 & 539 & 1 & 64 & 17 \\
$100-125$ & 37 & 586 & 105 & 0 & 10 & 355 \\
$125-150$ & 90 & 151 & 57 & 0 & 9 & 4 \\
$150-175$ & 29 & 40 & 0 & 0 & 14 & 0 \\
$175-200$ & 0 & 0 & 0 & 0 & 1 & 0 \\
$200-225$ & & & & &
\end{tabular}

The data is then processed for clustering the ship according to ship length and ship type. The clustering is an important step in order to conduct further analysis in IWRAP Mk2 software. Moreover, the ship clustering is also used for determining collision frequency for each ship type. Table 1 shows the result of ship clustering according to its length and type. The average of ship length and breadth for each group will be used in the analysis.

\subsection{Ship Collision Analysis}

There are three scenarios of collision are considered in this study namely crossing collision, head-on collision, and overtaking collision. The frequency of ship collision can be estimated either using statistical method or mathematical method. Statistical methods give more advantage for providing realistic figures but it will be difficult for future prediction because the situation may differ 
from today. And the mathematical methods illustrate the real phenomena and can be used to predict ship collision frequency in the future [4]. Fujii et al. developed a mathematical approach for estimating the ship collision frequency. The Fujii's models is expressed as (1) [5]:

$$
N=N_{a} \times P_{c}
$$

Where $N$ is the number of ship collision frequency; $\mathrm{Na}$ is the value of ship collision candidate; and $P c$ is the causation factor which is defined as the probability of failing to avoid a collision. In this analysis, the mathematical method to calculate the geometric number and probability of collision follows the IWRAP theory which is developed by Friis-Hansen.

\subsubsection{Crossing Collision Analysis}

The frequency of crossing collisions depends on the angle between the two lanes [3]. The geometric number which is defined as the candidate of ship in crossing collision will be considered then. The data which is used for this analysis can be summarized as follow:

- Length of ships $\left(L_{i}, L_{j}\right)$ represents the length of ship groups sail in the way- $i$ and way-j.

- Breadth of ships $\left(B_{i}, B_{j}\right)$ represents the breadth of ship groups sail in the way- $i$ and way- $j$.

- Speed of ships $\left(V_{i}, V_{j}\right)$ represents the velocity of ship groups sail in the way- $i$ and way-j.

- Angle $(\theta)$ between two lanes.

- Quantity of ships $\left(Q_{i}, Q_{j}\right)$ represents the quantity of ship groups sail in the way- $i$ and way- $j$ for a particular time range

The angle between two shipping lanes are considered as illustrated in Figure 2.

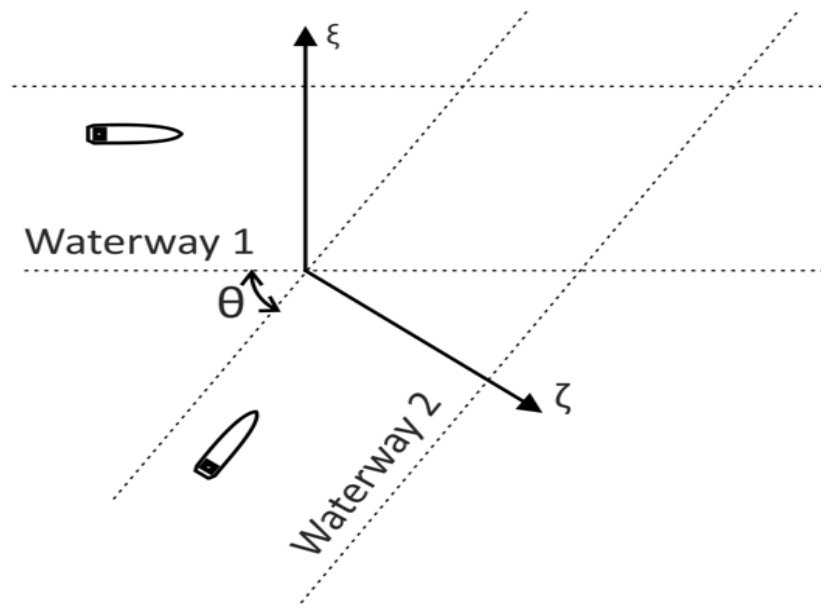

Figure 2: Illustration of crossing shipping lanes to consider the angle of crossing

The geometric number represents the ship candidate of collision which is calculated using (2):

$$
N_{G}^{\text {crossing }}=\sum_{i, j} \frac{Q_{i} Q_{j}}{V_{i} V_{j}} D_{i j} V_{i j} \frac{1}{\sin \theta}
$$

The relative velocity $\left(V_{i j}\right)$ and the diameter of collision $\left(D_{i j}\right)$ need to be determined using (3) and (4).

$$
\begin{gathered}
V_{i j}=\sqrt{\left(V_{i}\right)^{2}+\left(V_{j}\right)^{2}-2 \times V_{i} \times V_{j} \times \cos \theta} \\
D_{i j}=\frac{L_{i} V_{j}+L_{j} V_{i}}{V_{i j}} \sin \theta+B_{j}\left\{1-\left(\sin \theta \frac{V_{i}}{V_{i j}}\right)^{2}\right\}+B_{i}\left\{1-\left(\sin \theta \frac{V_{j}}{V_{i j}}\right)^{2}\right\}
\end{gathered}
$$


In this crossing collision scenario, the number of causation probability $(P c)$ is determined according to Mulyadi and the value of causation probability $(P c)=1.08 \times 10^{-4}[1]$.

\subsubsection{Head on and Overtaking Collision Analysis}

Both of head on and overtaking collision are a lateral condition of ship collision where the candidate of collision are distributed along the length of the segment. The data which is needed to analyze both of collision are:

- The length of segment $\left(L_{w}\right)$

- The quantity or frequency of each ship types which are analyzed $\left(Q_{i}\right)$ and $\left(Q_{j}\right)$.

- The geometrical probability distribution $f_{i}(y)$ and $f_{j}(y)$, of lateral traffic for head on and overtaking collision are spread along the route. The distribution can be defined as normal distribution along the route but actually it can be any type distribution.

The Figure 3 is the illustration of lateral ship collision condition such as head on and overtaking collision condition.

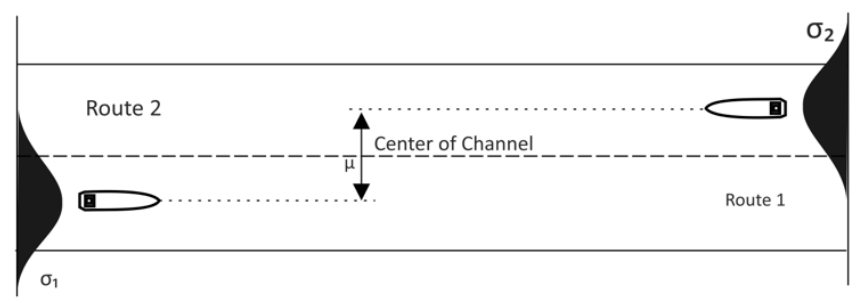

Figure 3: Illustration of lateral ship collision condition

Where the value of geometric number can be calculated as in (5)

$$
N_{G}=L_{W} \sum_{i, j} P_{G i j}^{\text {headon }} \frac{V_{i j}}{V_{i} V_{j}}\left(Q_{i} Q_{j}\right)
$$

The value of relative velocity between head on collision and overtaking collision are calculated as in (6) and (7),

$$
\begin{aligned}
V_{i j}=V_{i} & +V_{j} \text { for head on collision } \\
& V_{i j}=V_{i}-V_{j} \text { for overtaking collision }
\end{aligned}
$$

The other data that shall be determined are the length of segment $(L w)$. The value of $P_{G}$ as probability of collision can be calculated by (8).

$$
P_{g}=\phi\left(\frac{B_{i j}-\mu_{i j}}{\sigma_{i j}}\right)-\phi\left(-\frac{B_{i j}+\mu_{i j}}{\sigma_{i j}}\right)
$$

To calculate the value of collision probability, the data shall be determined such as: $\Phi(x)$, defined as the normal distribution function.

Mean $(\mu i j)$, can be calculated using formula as in (9).

$$
\mu_{i j}=\mu_{i}+\mu_{j}
$$

Standard deviation $\left(\sigma_{i j}\right)$, can be determined using formula as in (10).

$$
\sigma_{i j}=\sqrt{\left(\sigma_{i}\right)^{2}+\left(\sigma_{j}\right)^{2}}
$$

The average of breadth $\left(B_{i j}\right)$, for both groups of ships using formula as in (11). 


$$
B_{i j}=\frac{B_{i}+B_{j}}{2}
$$

By using the formula as in (5), the result of head on collision and overtaking collision are $9.1762 \times 10^{-3}$ and $6.7392 \times 10^{-3}$. The value of causation probability for head-on collision and overtaking collision are $5 \times 10^{-5}$ and $11 \times 10^{-4}$. The result for head-on and overtaking collision shows that the risk are acceptable. The probability of ship collision with head on collision and overtaking collision are less than 1 accident per year.

\section{Ship Collision Consequence Analysis}

Collision is one of factors which caused structural damage for both struck ship and striking ship. Damage of the structure will lead into more serious problem such as marine pollution because of the oil spill and chemical spill. For example is the environmental damage caused by the 'Exxon Valdez'. In this paper, the behavior of materials when ships are collided will be analyzed using 3D model and the energy is dissipated when collision happen will be analyzed using mathematical methods.

According to the Zhang (1999), the analysis procedures are divided into two parts; the external dynamics and internal mechanics [3]. The external dynamics is developed to examine the collision energy loss and the impact in ship-ship collision. The internal mechanics is a series of damage analysis to examine basic structural elements. Ship collision consequence analysis is conducted to analyze the damage structure of ship as the impact of ship collision. The structural damage can be analyzed using several methods such as experiment, analysis using software, or using mathematical method. Mathematical methods can be used to determine the energy which is dissipated when ships are collided. And the value of dissipated energy can be stated according to the level of damage of ship structure.

Figure 4 is the illustration of ship collision consequence analysis where the shuttle vessel and another vessel are collided. The coordinate of collision in the mathematical method shall be determined as $\left(x_{c}, y_{c}\right)$ to represent the position of shuttle vessel. $\eta$ represent the direction of other vessel to the shuttle vessel. The angle between $\eta$-axis and $x$-axis is symbolized as $\alpha$, and $\xi$ represents the direction of shuttle vessel to the other vessel.

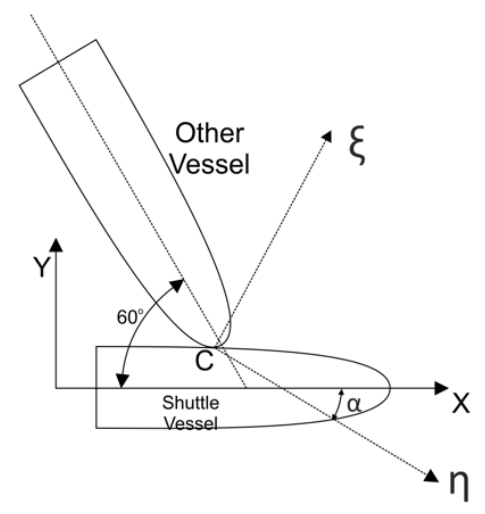

Figure 4: Illustration of ship collision consequence analysis

The angle is determined as the line of centerline of other vessel to the centerline shuttle vessel. The equation to calculate the energy which is dissipated during collision using (12).

$$
E \xi=\frac{1}{2} \times \frac{1}{D \xi \times \mu \times D \eta}
$$

The value of $D_{\xi}$ and $D_{\eta}$ can be calculated by using (13) and (14). 


$$
\begin{aligned}
& D \xi=\frac{D a \xi}{M a}+\frac{D b \xi}{M b} \\
& D \eta=\frac{D a \eta}{M a}+\frac{D b \eta}{M b}
\end{aligned}
$$

The relative velocity after collision is expressed by equation (15).

$$
\xi=V_{a x} \cos \alpha+V_{a y} \sin \alpha-V_{b 1} \cos (\beta-\alpha)-V_{b 2} \sin (\beta-\alpha)
$$

Where, the value of each equation components are determined by (16) to (23).

$$
\begin{aligned}
& D_{\alpha \xi}=\frac{1}{1+m_{a y}} \cdot \sin ^{2} \alpha+\frac{1}{1+m_{a y}} \cdot \cos ^{2} \alpha+\frac{1}{1+j_{a}} \cdot \frac{\left[y_{c} \cdot \sin \alpha-\left(x_{c}-x_{a}\right) \cdot \cos \alpha\right]^{2}}{R \alpha^{2}} \\
& D_{\alpha \eta}=\frac{1}{1+m_{a x}} \cdot \sin \alpha \cdot \cos \alpha+\frac{1}{1+m_{a y}} \cdot \sin \alpha \cdot \cos \alpha+\frac{1}{1+j_{a}} \cdot \frac{\left[y_{c} \cdot \sin \alpha-\left(x_{c}-x_{a}\right) \cdot \cos \alpha\right]\left[y_{c} \cdot \cos \alpha+\left(x_{c}-x_{a}\right) \cdot \sin \alpha\right]}{R a^{2}} \\
& D_{a \eta}=0.398 \\
& D_{b \xi}=\frac{1}{1+m_{b 1}} \cdot \sin (\beta-\alpha)+\frac{1}{1+m_{b 2}} \cdot \sin (\beta-\alpha) \cos (\beta-\alpha)+\frac{1}{1+j_{b}} \cdot \frac{\left[\left(y_{c}+y_{b}\right) \sin \alpha-\left(x_{c}-x_{a}\right) \cos \alpha\right]\left[\left(y_{c}-y_{b}\right) \cdot \cos \alpha+\left(x_{c}-x_{b}\right) \cdot \sin \alpha\right]}{R_{b}} \\
& D_{b \xi}=1.219 \\
& D_{b \eta}=\frac{1}{1+m_{b 1}} \cdot \sin (\beta-\alpha) \cdot \cos (\beta-\alpha)+\frac{1}{1+m_{b 2}} \cdot \sin (\beta-\alpha) \cdot \cos (\beta-\alpha)+\frac{1}{1+j_{b}} \cdot \frac{\left[\left(y_{c}-y_{b}\right) \cdot \sin \alpha-\left(x_{c}-x_{a}\right) \cdot \cos \alpha\right]\left[\left(y_{c}-y_{b}\right) \cdot \cos \alpha+\left(x_{c}-x_{b}\right) \cdot \sin \alpha\right]}{R_{b}} \\
& D_{b \eta}=-0.3006 \\
& K_{a \xi}=\frac{1}{1+m_{a x}} \cdot \sin \alpha \cdot \cos \alpha-\frac{1}{1+m_{a y}} \cdot \sin \alpha \cdot \cos \alpha+\frac{1}{1+j_{a}} \cdot \frac{\left[y_{c} \cdot \sin \alpha-\left(x_{c}-x_{a}\right) \cdot \cos \alpha\right]\left[y_{c} \cdot \cos \alpha+\left(x_{c}-x_{a}\right) \cdot \sin \alpha\right]}{R_{a}^{2}} \\
& K_{a \xi}=1.417 \\
& K_{a \eta}=\frac{1}{1+m_{a x}} \cdot \cos ^{2} \alpha+\frac{1}{1+m_{a y}} \cdot \sin ^{2} \alpha+\frac{1}{1+j_{a}} \cdot \frac{\left[y_{c} \cdot \cos \alpha+\left(x_{c}-x_{a}\right) \sin \alpha\right]^{2}}{R_{a}^{2}} \\
& K_{a \eta}=0.8032 \\
& K b \xi=\frac{1}{1+m b_{1}} \sin (\beta-\alpha) \cos (\beta-\alpha)+\frac{1}{1+m b_{2}} \sin (\beta-\alpha) \cos (\beta-\alpha)+\frac{1}{1+j b} \cdot \frac{[(y c-y b) \sin \alpha-(x c-x b) \cos \alpha][(y c-y b) \cos \alpha-(x c-x b) \sin \alpha]}{R b^{2}} \\
& K_{b \xi}=-0.1675 \\
& K b \eta=\frac{1}{1+m b_{1}} \cos ^{2}(\beta-\alpha)+\frac{1}{1+m b_{2}} \sin ^{2}(\beta-\alpha)+\frac{1}{1+j b} \cdot \frac{[(y c-y b) \cos \alpha+(x c-x b) \sin \alpha]^{2}}{R b^{2}} \\
& K_{b \eta}=0.8154
\end{aligned}
$$

Where, the number of following mathematical equation components are,

- $M_{a}$, the mass of ship A

- $M_{b}$, the mass of ship B

- $\quad m_{a x}$ and $m_{b l}$, represent the coefficient of mass ship A and ship B in surge motion there the value range is $0.02-0.07$

- $\quad m_{a y}$ and $m_{b 2}$, represent the coefficient of mass at sway motion of ship A and ship B where the value range is $0.3-1.3$

- $j_{a}$ and $\mathrm{j}_{\mathrm{b}}$ is the coefficient of ship mass at yaw motion where the value is 0.21

- $\left(x_{a}, 0\right)$ is the coordinate of the center of gravity for ship A as striking vessel

- $\left(x_{b}, y_{b}\right)$ is the coordinate of the center of gravity for ship B as struck vessel

- $\mathrm{R}$ is the radius of ship inertia where the value is $1 / 4$ of the length of perpendicular 
- $\quad V_{a y}$ is the ship A velocity after collision and $V_{b 2}$ is the ship B velocity after collision where the value of the coefficient of friction between two ship is $\mu_{0}=0.6$

The energy which is dissipated when the collision is happened will be classified according to the criteria as follows:
- 0 to $30 \mathrm{MJ}$
$=$ minor damage
- 30 to $100 \mathrm{MJ} \quad=$ moderate damage
- 100 to $200 \mathrm{MJ} \quad=$ heavy damage
- $<200 \mathrm{MJ} \quad=$ critical damage

The analysis of ship collision consequence is also conducted using $3 \mathrm{D}$ modelling to analysis the external dynamics of ship collision. In this analysis, there are two geometric parts which are used in $3 \mathrm{D}$ modelling, the first is midship section as the struck vessel with dimension (length $=14.58$ meters, width $=10$ meters, and height $=10$ meters) and the forepeak section as the striking vessel with dimension (length $=12.88$ meters, width $=7.45$ meters, and the height $=12.5$ meters). The angle of collision is $90^{\circ}$, and the velocity of collision is $3.4 \mathrm{~m} / \mathrm{s}$ where the density of sea water $1.025 \mathrm{~kg} / \mathrm{m}^{3}$, force magnitude $1 \times 10^{8} \mathrm{~N}$, and the gravity is $9.81 \mathrm{~m} / \mathrm{s}^{2}$.

\section{Result and Discussion}

The result of ship collision frequency analysis is conducted using mathematical method according to the IWRAP Theory and analysis using IWRAP Software and will be validated by comparing the both of result. The result of manual calculation for crossing collision is $2.152 \times 10^{-2}$. The result of head on collision and overtaking collision are $9.1762 \times 10^{-3}$ and $6.7392 \times 10^{-3}$. The value of causation probability for head-on collision and overtaking collision are $5 \times 10^{-5}$ and $11 \times 10^{-4}$ are taken from the default value of causation probability which are determined by IWRAP Software. The result for head-on and overtaking collision shows that the risk are acceptable. The probability of ship collision with head on collision and overtaking collision are below 1 accident per year. So, according to the result the risk is considered as safe for vessel operation.

Validation process is used to check whether or not there is a human error or incorrect calculation during manual process. The validation process is conducted by comparing the results of manual process and IWRAP software analysis. The validation process of crossing collision as follows,

- Result of manual calculation $=2.152 \times 10^{-2}$

- Result of IWRAP Software $=2.3002 \times 10^{-2}$

The validation result of crossing collision using data above is $93.55 \%$.

The validation process of head on collision and overtaking collision between manual method and IWRAP software are conducted using sample of data. And the result of validations are,

- Validation process of Head On Collision

- $\quad$ Result of manual calculation $=2.16 \times 10^{-4}$

- Result of IWRAP software $=2.104 \times 10^{-4}$

The validation result of head on is $97.15 \%$

- Validation process of Overtaking Collision

- $\quad$ Result of manual calculation $=1.59 \times 10^{-4}$

- Result of IWRAP software $=1.55 \times 10^{-4}$

The validation result of head on is $98.05 \%$ 
The validation process is not completely similar between manual calculation and IWRAP software, it may be affected by the way to determine the value such as angle for crossing collision and breadth for overtaking and head on collision. The software is determined the value automatically using system and ratio. While for manual calculation, the values are determined using actual data/ static data.

The ship collision consequence analysis is conducted to analyze the damage structure of ship as the impact of ship collision. The structural damage can be analyzed using several methods such as experiment, analysis using software, or using mathematical method. Mathematical methods can be used to determine the energy which is dissipated when ships are collided. The result of the energy dissipated calculation using mathematical method is $44.312 \mathrm{MJ}$. It can be categorized as moderate damage will occur after collision. The analysis using 3D model is used to determine several effect of ship collision such as:

a. Total deformation which is occurred in the midship section.

b. The value of directional deformation to the model.

c. The value of equivalent stress of midship section and forepeak section collision.

Table 2 shows the result of 3D modelling of structural damage analysis as the impact of ship collision. The data is obtained by conducting 3D modelling analysis of 2 solid part of ships body; midship section body and forward section body to collect the data of total deformation, the directional deformation, and the equivalent stress value which is occurred in ship collision.

Table 2: The result of 3D modelling

\begin{tabular}{|c|c|c|c|}
\hline Analysis & Minimal Value & Maximal Value & Unit \\
\hline Total Deformation & $2,5743 \times 10^{-4}$ & $1,6928 \times 10^{-1}$ & meter \\
\hline $\begin{array}{c}\text { Directional } \\
\text { Deformation }\end{array}$ & $-7,2658 \times 10^{-3}$ & $1,6816 \times 10^{-1}$ & meter \\
\hline Equivalent Stress & 70253 & $3,9607 \times 10^{9}$ & Pascal \\
\hline
\end{tabular}

\section{Conclusion}

The result of ship collision analysis using mathematical method to calculate the frequency of collision shows that the risk can be considered as acceptable risk and the frequency is less than 1 accident per year. It can be considered that the shipping lane is still safe. As the recommendation and the mitigation for the future, the development of Surabaya West Access Channel is needed to accommodate the enhancement of ship traffic in the future so the risk level can be maintained. The result of validation shows that the validation are acceptable and reach more than $90 \%$ of validation.

The result of ship collision consequence analysis can be considered as moderate damage according to the calculation. In the other hand, the result of 3D modelling is not fully represent the actual condition. Hence, the 3D model result cannot be the standard of ship collision consequence. It needs more study and development to analysis the effect of collision due to the structural damage.

\section{References}

[1] Y. Mulyadi, E. Kobayashi, N. Wakabayashi, T. Pitana, and Wahyudi, "Development of ship sinking frequency model over Subsea Pipeline for Madura Strait using AIS data,” WMU J. Marit. Aff., vol. 13, no. 1, pp. 43-59, 2014.

[2] P. F. Hansen, IWRAP MK II : Basic Modelling Principles for Prediction of Collision and Grounding Frequencies. Technical University of Denmark, 2007.

[3] S. Zhang, The mechanics of ship collisions. Institute of Naval Architecture and Offshore Engineering, 1999. 
[4] P. T. Pedersen, "Review and application of ship collision and grounding analysis procedures," Mar. Struct., vol. 23, no. 3, pp. 241-262, 2010.

[5] Y. Fujii and K. Tanaka, "Traffic Capacity," J. Navig., vol. 24, no. 4, pp. 543-552, 2010. 